\title{
Staphylococcus saprophyticus L-38 produces volatile 3,3-dimethyl-1,2-epoxybutane with strong inhibitory activity against Aspergillus flavus germination and aflatoxin production
}

\author{
A.D. Gong ${ }^{1,2,3 \#}$, G.J. Sun ${ }^{1,3 \#}$, Z.Y. Zhao ${ }^{4}$, Y.C. Liao ${ }^{1,3}$ and J.B. Zhang ${ }^{1,3^{*}}$ \\ ${ }^{1}$ Molecular Biotechnology Laboratory of Triticeae Crops, Huazhong Agricultural University, Wuhan 430070, China P.R.; \\ ${ }^{2}$ College of Life Science, Xinyang Normal University, Xinyang 464000, China P.R.; ${ }^{3}$ College of Plant Science and Technology, \\ Huazhong Agricultural University, Wuhan 430070, China P.R.; ${ }^{4}$ Institute for Agro-food Standards and Testing Technology, \\ Laboratory of Quality \& Safety Risk Assessment for Agro-products (Shanghai), Ministry of Agriculture, Shanghai Academy \\ of Agricultural Sciences, Shanghai 200031, China P.R.; jingbozhang@mail.hzau.edu.cn; \# these authors contributed equally \\ to this work
}

Received: 2 July 2019 / Accepted: 27 August 2019

(c) 2019 Wageningen Academic Publishers

OPEN ACCESS CC)@(1) RESEARCH ARTICLE

\begin{abstract}
Controlling proliferation and aflatoxin production by Aspergillus flavus is a pressing challenge for global food safety and security. Marine bacterium Staphylococcus saprophyticus strain L-38 showed excellent antifungal activity toward A. flavus in vitro and in vivo. In sealed, non-contact confrontation assays, L-38 completely inhibited conidial germination and mycelial growth of $A$. flavus through the production of volatile organic compounds (VOCs). Gas chromatography-mass spectrometry identified 3,3-dimethyl-1,2-epoxybutane (3-DE) as the most abundant VOC (32.61\% of total peak area, 78\% matching). Exposure of A. flavus cultures to synthetic 3-DE similarly demonstrated strong inhibition of growth. Moreover, culture of L-38 in a sealed chamber with maize or peanuts artificially inoculated with $A$. flavus, at high water activity, resulted in significant inhibition of $A$. flavus germination and aflatoxin biosynthesis. Scanning electron microscopy of these samples revealed severe damage to conidial cells and hyphae compared to samples not exposed to L-38. L-38 also showed broad and effective antifungal activity toward eight other phytopathogenic fungi including Aspergillus niger, Fusarium verticillioides, Fusarium graminearum, Sclerotinia sclerotiorum, Rhizoctonia solani, Alternaria alternata, Monilinia fructicola, and Botrytis cinerea. This work introduces S. saprophyticus L-38 as a potential biocontrol agent and demonstrates the efficacy of the volatile 3 -DE in the control of A. flavus and other destructive plant pathogens for post-harvest food safety.
\end{abstract}

Keywords: Aspergillus flavus, aflatoxin, post-harvest, Staphylococcus saprophyticus, volatile organic compound, 3,3-dimethyl1,2-epoxybutane

\section{Introduction}

Aspergillus flavus is a ubiquitous pathogen that infects many economically important crops during both preand post-harvest stages, such as maize, peanut, rice, and cottonseed among others (Asters et al., 2014; Kamika and Takoy, 2011). This filamentous ascomycete produces highly toxic and carcinogenic aflatoxins which cause severe health problem to humans. Thus far, eighteen unique aflatoxins have been identified from Aspergillus species, and four of them, aflatoxin $\mathrm{B}_{1}, \mathrm{~B}_{2}, \mathrm{G}_{1}, \mathrm{G}_{2}\left(\mathrm{AFB}_{1}, \mathrm{AFB}_{2}, \mathrm{AFG}_{1}, \mathrm{AFG}_{2}\right)$, are frequently detected in food/feed products (Malachová et al., 2014). For this reason, these four aflatoxins are classified as a Group I carcinogen for humans by the International Agency for Research on Cancer (IARC) (IARC, 2002; Robens and Cardwell, 2003). Currently, over 5 billion people worldwide reportedly suffer from unmitigated exposure to aflatoxin-contaminated crops (Strosnider et al., 2006). Additionally, among these toxins, $\mathrm{AFB}_{1}$ is reported to be the most dangerous, both toxic and carcinogenic, for humans and farm animals.

Compounding this problem, aflatoxins may act synergistically in hepatitis C-infected people, resulting 
in liver cancer, the third most common cause of cancerrelated deaths globally (Kirk et al., 2006; Kuang et al., 2015; Wild and Montesano, 2009). As of 2004, it was estimated that of the 550,000-600,000 yearly reported hepatocellular carcinoma cases, 25,200-155,000 may be directly related to aflatoxin exposure (Ogodo and Ugbogu, 2016). Moreover, recorded cases of acute aflatoxicosis are increasing, resulting in extraordinarily high death tolls in developing countries (Waliyar et al., 2015). In 2004-2005, over 150 people died from consumption of aflatoxin-contaminated maize in Kenya (Amaike and Keller, 2011). In response to the threat aflatoxins pose to humans, more than 100 countries have legislatively established the maximum levels of aflatoxins intended for human and animal consumption (Bui-Klimke et al., 2014). However, due to chronic food shortages in developing nations, particularly in Africa, many countries have eased or removed these restrictions, leading to serious local outbreaks of aflatoxin-related health problems (Kamika and Takoy, 2011).

Hence, the most effective method for avoiding the accumulation of aflatoxins in food supplies is to prevent the production of aflatoxins in the field and at harvest. Without consideration for environmental factors, several methods have been successfully employed in the field for control of $A$. flavus and aflatoxin production, such as breeding resistant crops, chemical control, and biological control (Ashworth et al., 1965; Buchanan et al., 1987; Dorner, 2004; Wicklow et al., 1980; Wu and Khlangwiset, 2010). After harvest, management of $A$. flavus infestation depends on safe storage and treatment with chemical pesticide agents. Recently, volatile anti-fungal compounds from plants have been widely examined for use in post-harvest A. flavus control, such as Peumus boldus, Lippia turbinata (Passone and Etcheverry, 2014), clove (Eugenia caryophillis) (Thobunluepop, 2009), Cuminum cyminum (Kedia et al., 2014), Cymbopogon citratus (lemongrass) (Paranagama et al., 2003), and soybean (Cleveland et al., 2009). The primary obstacle in wider adoption of these plant-based volatile organic compounds (VOCs) is the limitation on quantity that can be easily collected, and time required to extract the active ingredients (Zhang et al., 2011).

To resolve this issue, microbes have been proposed as acceptable sources for anti-fungal metabolites due to their ease of culture and compound extraction (Kelecom, 2002). In our previous work, we showed that the algae strain Shewanella sp. YM8 produces volatile dimethyl trisulfide that greatly inhibits the growth of A. flavus, and subsequent aflatoxin contamination in post-harvest crops (Gong et al., 2015a). While this strain may be used as a biocontrol agent or source of anti-fungal compound dimethyl trisulfide for controlling post-harvest fungal diseases, the application of microbes or their metabolites for post-harvest control of $A$. flavus and aflatoxin is still being tested. However, in light of the rapid emergence of pathogen tolerance to fungicides and environmental requirement, we seek to identify and validate an array of novel and effective bacterial strains that produce anti-microbial substances for potential deployment against $A$. flavus and other fungal threats to food security.

In this study, we identified the marine bacterium Staphylococcus saprophyticus strain L-38 and explored its ability to produce volatile secondary metabolites with strong antagonistic activity against $A$. flavus. To characterise the biocontrol activity of strain L-38, we measured its inhibitory activity against aflatoxin biosynthesis, profiled the pattern of VOCs produced during A. flavus confrontation, and elucidated their mechanisms of suppression toward germination of $A$. flavus conidia. We demonstrated that strain L-38 could produce seven volatile compounds, and that the main antagonistic factor, 3,3-dimethyl-1,2epoxybutane (3-DE) accounted for the largest proportion of and activity of these compounds. Production of 3-DE by strain L-38 greatly inhibited A. flavus mycelial growth and conidial germination, as well as the proliferation of eight other phytopathogenic species of filamentous fungi. Moreover, this strain could control A. flavus growth and aflatoxin production in post-harvest peanuts and maize with different moisture contents. We could conclude that strain L-38 and 3-DE are effective biocontrol agents with great potential for agricultural adoption and deployment in control of fungal plant pathogens and post-harvest contamination.

\section{Materials and methods}

\section{Microorganisms and crop kernels}

Strain L-38 used in the tests was isolated from Yellow Sea marine sediment close to Yantai, China. The strain was cultured on nutrient agar (NA) plates (Gong et al., 2015a) to produce volatile compounds. Bacterial suspensions in $25 \%$ glycerol were kept at $-80^{\circ} \mathrm{C}$ for long-term storage. Mature maize kernels (cultivar Zhengdan 958) and peanuts (cultivar Silihong) were purchased from local markets (Wuhan, China), inoculated with A. flavus conidia and challenged with L-38 for biocontrol assays.

Nine phytopathogens were used to identify the antagonistic spectrum of strain L-38. The pathogens, including Aspergillus flavus 12, Aspergillus niger 27, Fusarium verticillioides 5047, and Fusarium graminearum 5035 were isolated from infected peanuts and scabby wheat grains, stored in our lab (Gong et al., 2015b) and available for researches under request. Fungal strains including Sclerotinia sclerotiorum, Rhizoctonia solani, Alternaria alternata, Monilinia fructicola, and Botrytis cinerea were kindly provided by the National Key Laboratory of Agromicrobiology, Huazhong Agricultural University, China P.R. 


\section{DNA extraction and phylogenetic alignment}

L-38 was cultured in nutrient broth (NB) medium at 200 rpm and $28^{\circ} \mathrm{C}$ for $48 \mathrm{~h}$ for DNA extraction (Li et al., 2017). The 16S rRNA sequences were amplified by PCR with primers and conditions as previously described (Gong et al., 2015a). Amplicon fragments were sequenced (BGI, Wuhan, China P.R.) and the obtained sequences homologous to the L-38 16S rRNA were identified using BLAST (National Center for Biotechnology Information, http://www.ncbi. nlm.nih.gov). The phylogenetic tree based on $16 \mathrm{~S}$ rRNA sequence of strain L-38 and homologous sequences from 25 bacterial species was reconstructed using the neighbourjoining evolutionary model (Ding et al., 2015; Gao et al., 2018; Guo et al., 2013; Han et al., 2015) with MEGA 6 software.

\section{Antagonistic activity of strain L-38 against Aspergillus flavus mycelia and conidia}

Antifungal activity assays of VOCs from L-38 against $A$. flavus conidia and mycelia were conducted in sealed petri dishes (90 mm in diameter) (Fernando et al., 2005). Fresh A. flavus conidia were collected as previously described (Gong et al., 2015a). A. flavus conidia $\left(5 \mu \mathrm{l}\right.$ at $10^{5} \mathrm{cfu} / \mathrm{ml}$ ) were inoculated into potato dextrose broth (PDB) medium and cultured at $150 \mathrm{rpm}$ and $28{ }^{\circ} \mathrm{C}$ for 2 days to produce mycelial coils.

Fresh L-38 cells $\left(100 \mu \mathrm{l}\right.$ at $\left.10^{8} \mathrm{cfu} / \mathrm{ml}\right)$ were spread on NA plates, which were placed face up, while $A$. flavus mycelial coils were inoculated to the centre of PDA plates and placed face down, on top of the NA plates, directly facing, though not in contact with the L-38 colonies. The two plates were thus sealed 'face-to-face' and incubated at $28^{\circ} \mathrm{C}$ for 3 days. PDA plates inoculated with $A$. flavus mycelial coils and cocultured with uninoculated NA plates were used as controls. The inhibition rate of L-38 was calculated as follows:

Inhibition rate $(\%)=[$ the diameter of control - the diameter of antagonist treatment)/the diameter of control] $\times 100$

A. flavus conidia $\left(100 \mu \mathrm{l}, 10^{5} \mathrm{cfu} / \mathrm{ml}\right)$ spread over glass paper on a PDA plate were challenged with L-38 spread on an NA plate, sealed together in a single space. The characteristics of germinating conidia were observed and recorded with a microscope (Nikon 90i eclipse, Tokyo, Japan) at 2 days post inoculation (dpi). The conidial germination rate was tested using methods previously described (Gong et al., 2015a).

\section{Identification of volatile organic compounds and inhibition of fungal growth}

The identification of VOCs produced by strain L-38 was conducted with solid-phase micro-extraction (SPME) fibre containing divinylbenzene/carboxen/polydimethlsiloxane and a GC-MS system (5975B-7890N, Agilent Technologies Inc., Santa Clara, CA, USA) (Gong et al., 2015a). Briefly, strain L-38 was spread on the surface of NA medium (40 $\mathrm{ml}$ ) in a $100 \mathrm{ml}$ flask. The flask was sealed with plastic membrane. Another flask containing NA medium was used as control. All flasks were placed at $28^{\circ} \mathrm{C}$ and darkness for $48 \mathrm{~h}$. The flasks were placed in $40{ }^{\circ} \mathrm{C}$ water bath and equilibrated for $30 \mathrm{~min}$. A SPME fibre was pierced into the flask for $30 \mathrm{~min}$ for volatiles absorbing and analysed through GC-MS (5975B-7890N, Agilent Technologies Inc.) instrument by splitless injection mode using an Agilent DB-5MS $(30 \times 0.25 \mathrm{~mm}$ ID, $0.25 \mu \mathrm{m}$ thickness film) fused-C18 capillary. The test was conducted by manual injector method. For GC-MS analysis, the inlet temperature is $250{ }^{\circ} \mathrm{C}$, the flow rate is $1 \mathrm{ml} / \mathrm{min}$. The compounds were analysed as follows: $40^{\circ} \mathrm{C}$ for $3 \mathrm{~min} ; 3^{\circ} \mathrm{C} / \mathrm{min}$ to $160^{\circ} \mathrm{C}$, last for $2 \mathrm{~min} ; 8^{\circ} \mathrm{C} / \mathrm{min}$ to $220^{\circ} \mathrm{C}$, and last for $3 \mathrm{~min}$. For $\mathrm{MS}$ equipment, the temperature for $\mathrm{EI}$ ion source is $230{ }^{\circ} \mathrm{C}$, the quadrupole temperature is $150{ }^{\circ} \mathrm{C}$. MS analysis was used Full Scan mode ranged from $50-550 \mathrm{~m} / \mathrm{z}$. The experiment was performed twice. The compounds produced by L-38 in a sealed chamber in the presence of $A$. flavus, were compared with gas compounds sampled from a sealed chamber in the absence of strain L-38, and those found only in the presence of L-38 were selected for further analysis. To determine the antifungal efficacy of 3,3-dimethyl-1,2epoxybutane (3-DE) produced by strain L-38, authentic reference standard was purchased (Sigma-Aldrich, USA), dissolved in ethanol and used for testing in the inhibition of $A$. flavus germination and growth. A. flavus conidia (10 $\mu \mathrm{l}$ of conidia at $5 \times 10^{5} \mathrm{cfu} / \mathrm{ml}$ ) were inoculated to paper disks in the centre of PDA plates. Disks on another petri dish were inoculated with the 3-DE standard to a final concentration of 5, 10, 100 and $200 \mu \mathrm{g} / \mathrm{l}$ (compound weight to airspace volume). Disks inoculated with ethanol were used as control. Two plates, one with A. flavus conidia and one with 3-DE were sealed face-to-face and incubated at $28{ }^{\circ} \mathrm{C}$ as for other assays in this study. The inhibition rate was calculated:

Inhibition rate $(\%)=[$ (the mycelia diameter of control the diameter of mycelia in 3-DE treatment)/the diameter of control] $\times 100$

\section{Control of Aspergillus flavus and aflatoxins on peanuts and maize with strain L-38}

Biocontrol effect of strain L-38 against $A$. flavus on maize and peanut were tested in a sealed desiccator ( 2.5 l airspace) with two levels of $\mathrm{a}_{\mathrm{w}}$. The peanut/maize kernels of $100 \mathrm{~g}$ in each flask were autoclaved at $121{ }^{\circ} \mathrm{C}$ for $20 \mathrm{~min}$, and then cooled to room temperature. $100 \mathrm{ml}$ of $A$. flavus conidia $\left(1 \times 10^{5} \mathrm{cfu} / \mathrm{ml}\right)$ was injected into each flask and mixed well for $10 \mathrm{~min}$. Sterilised water was added to adjust $\mathrm{a}_{\mathrm{w}}$ to 0.86 and 0.92 for maize and peanuts, respectively, using an electronic dewpoint water activity meter, Aqualab Series 
3 model TE (Decagon Devices, Pullman, WA, USA). The samples at each $\mathrm{a}_{\mathrm{w}}$ level were divided in half for two separate treatments. One half was challenged with strain L-38 (the bacteria streaked on NA plate at the bottom of the desiccator), while the other half was placed in another desiccator with uninoculated NA medium at the bottom as a control. The tests were conducted twice, and the maize and peanuts in separate treatments were collected $5 \mathrm{dpi}$ and dried at $60^{\circ} \mathrm{C}$. The dried samples were milled for further extraction and detection of aflatoxins. The disease incidence (\%) was calculated as 'pathogen-infected kernels/all kernels $\times 100$ '.

\section{Quantitative analysis of aflatoxins}

Aflatoxins in milled maize and peanuts were extracted with organic reagents. $1 \mathrm{~g}$ of milled sample was suspended in 5 $\mathrm{ml}$ acetonitrile:water $(84: 16, \mathrm{v} / \mathrm{v})$, vortexed for $1 \mathrm{~min}$, and sonicated for $60 \mathrm{~min}$. After centrifugation (12,000 rpm, 10 $\mathrm{min}$ ), the supernatant was transferred to a new tube. One $\mathrm{ml}$ of hexane (Tedia, Shanghai, China P.R.) was added in the tube, vortexed for $10 \mathrm{~min}$ and laid for stratification. The under layer was sampled and detected through Thermo Surveyor plus HPLC system coupled with a TSQ Quantum Ultra mass spectrometer (Thermo Scientific, San Jose, CA, USA). Chromatographic separation was achieved on Thermo Hypersil Gold column $(100 \times 2.1 \mathrm{~mm}, 3.0 \mu \mathrm{m})$ at $35{ }^{\circ} \mathrm{C}$, with a flow rate of $0.3 \mathrm{ml} / \mathrm{min}$. The mobile phase consisted of methanol (A) and water containing $5 \mathrm{mM}$ ammonium acetate and $0.05 \%$ formic acid (B). A linear gradient program was applied as follows: $0-1 \mathrm{~min}, 20 \% \mathrm{~A}$; 1-4 min, 20-100\% A; 4-5 min, $100 \%$ A; 5-5.5 min, 100-20\% A; $5.5-7 \mathrm{~min}, 20 \% \mathrm{~A}$. The sample injection volume was 5 $\mu \mathrm{l}$. The mass spectrometer was operated in positive mode $\left(\mathrm{ESI}^{+}\right)$. The following parameters were used for MS/MS analyses: spray voltage, $3.5 \mathrm{kV}$; vaporizer temperature, $350^{\circ} \mathrm{C}$; capillary temperature, $350^{\circ} \mathrm{C}$; sheath gas pressure, $40 \mathrm{psi}$; aux valve flow, $15 \mathrm{arb}$; collision gas pressure, 1.5 mTorr. Data were obtained and processed using Xcalibur software (Thermo Scientific). Aflatoxin reference standards $\left(\mathrm{AFB}_{1}, \mathrm{AFB}_{2}, \mathrm{AFG}_{1}\right.$ and $\mathrm{AFG}_{2}$ ) (Sigma-Aldrich, St. Louis, $\mathrm{MO}, \mathrm{USA}$ ) were used as standards for quantitative analysis.

\section{Ultra-structure analysis of Aspergillus flavus on infected peanuts}

Ultra-structure of $A$. flavus cells on infected peanut surfaces at $\mathrm{a}_{\mathrm{w}} 0.92$ were examined through JSM-4800 scanning electron microscopy (SEM) (Hitachi, Tokyo, Japan). Peanuts in control and L-38 treatments were fixed with $0.1 \%$ osmic acid for $1 \mathrm{~h}$, respectively. One small piece of the peanut coat was peeled off and affixed to SEM stubs. The samples were coated with gold and examined by SEM (Boukaew and Prasertsan, 2014).

\section{Broad antagonistic activity of strain L-38}

Broad antifungal activity of strain L-38 against other phytopathogens was tested with the face-to-face co-culture method described above. Fresh blocks ( $5 \mathrm{~cm}$ in diameter) of selected phytopathogens were individually inoculated to the centre of a PDA plate. Strain L-38 was spread on an NA plate and the two petri dishes were placed face-to-face, sealed with tape, and incubated at $28^{\circ} \mathrm{C}$ for 5 days. The inhibition rate was calculated according the methods used above.

\section{Data analysis}

Data were evaluated with one-way analysis of variance (ANOVA) using SAS 9.2 for windows (SAS Institute, Cary, NC, USA). Experiments were arranged in a complete randomised design with at least two replications. Mean comparisons were performed with Duncan's multiple range tests at a significance value of $P<0.05$.

\section{Results}

\section{Molecular identification and antifungal activity of Staphylococcus saprophyticus strain L-38 against Aspergillus flavus}

Strain L-38 was isolated from Yellow Sea marine sediments close to Yantai, China. The 16S rRNA of strain L-38 was sequenced and submitted to the NCBI (National Center for Biotechnology Information) Nucleotide Sequence Database (Accession number: MK645983). After a blast search was conducted using L-38 rRNA sequence as a query, a neighbour-joining phylogenetic tree was reconstructed using the sequence from L-38 with 25 homologous strains. We found that strain L-38 shared a sub-cluster with $S$. saprophyticus (AM9, CTSPL9, and CTSPL11 and others) and Staphylococcus xylosus (JCM 2418, C2a, and KL 162, and others) (Figure 1). The phylogenetic analysis combined with biochemical and physiological analysis (Schleifer and Kloos, 1975; Kloos and Schleifer, 1975) showing growth at $45^{\circ} \mathrm{C}$ and nitrate reduction, identified strain L-38 as a member of the S. saprophyticus species.

To better understand the capability for biological control against fungal phytopathogens by L-38, we employed modified confrontation assays between L-38 and $A$. flavus and observed the effects on A. flavus growth and development. We found that L-38 showed strong antifungal activity against $A$. flavus conidia and mycelia in sealed petri dishes. In this study, strain L-38 and A. flavus were directly opposite one another on NA (bottom) and PDA (up) plates, respectively, without physical contact. Conidial germination and mycelial growth of A. flavus were strongly inhibited, ostensibly by production of VOCs by L-38 which permeated the sealed airspace (Figure 2). The inhibition rate by strain L-38 against mycelial growth and conidial germination 


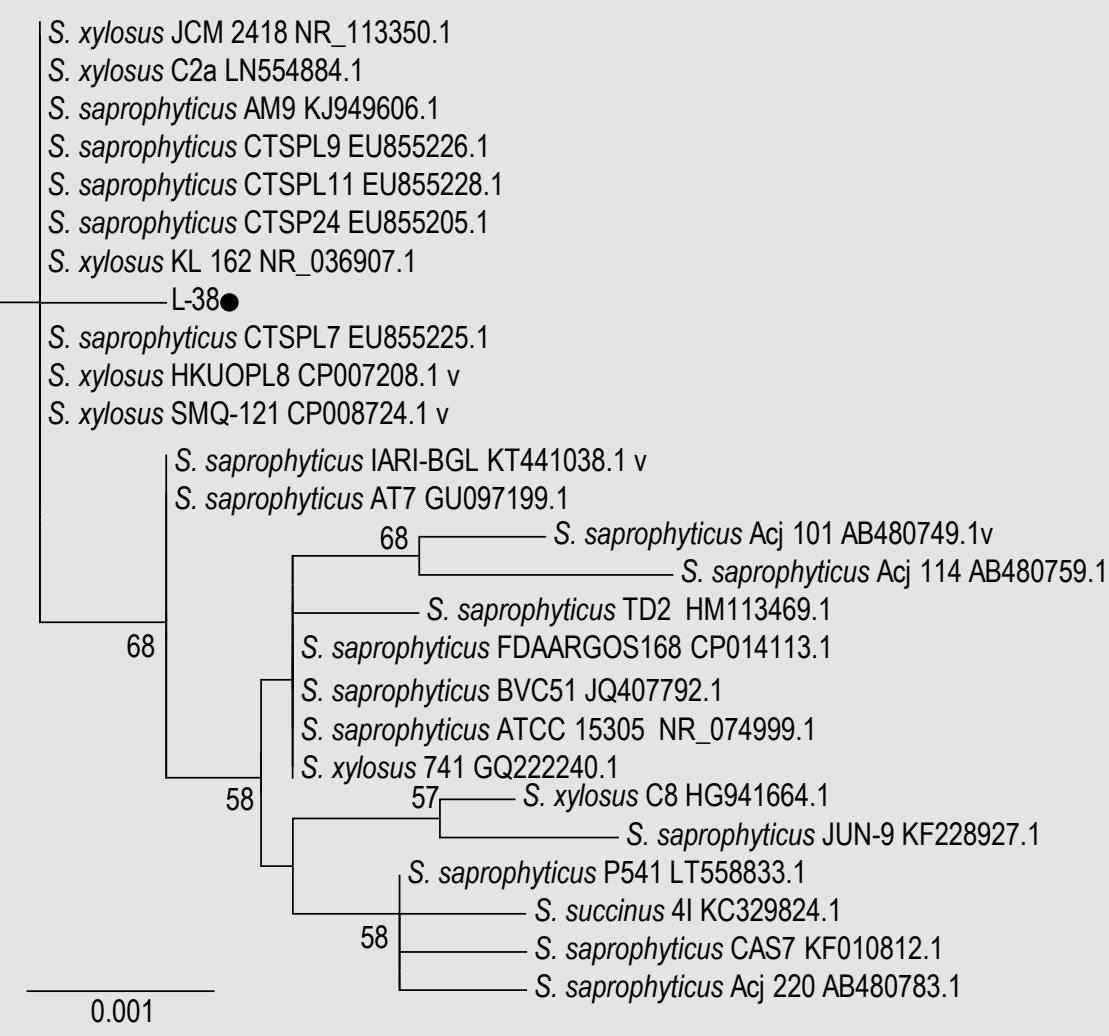

Figure 1. Neighbour-joining phylogenetic tree of $16 \mathrm{~S}$ rRNA sequences from strain L-38 and other 25 homologous Staphylococcus spp. The scale bar represents the number of substitutions per base position.

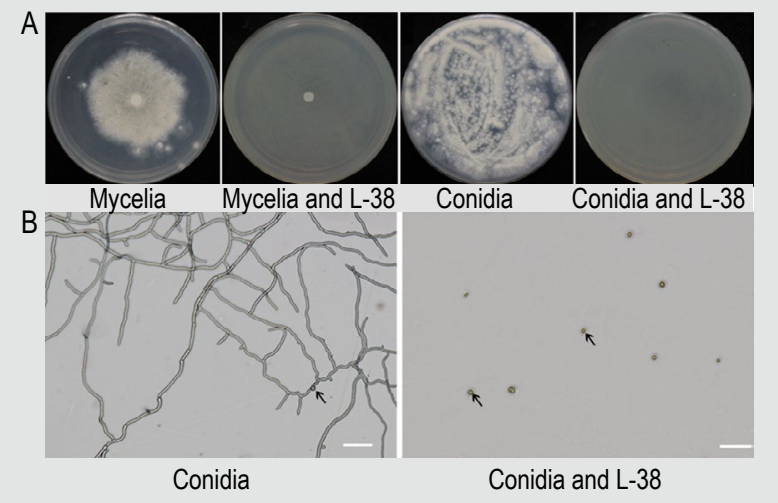

Figure 2. Inhibitory effect of volatiles from Staphylococcus saprophyticus strain L-38 against mycelial growth and conidial germination of Aspergillus flavus. (A) Mycelia and conidia of A. flavus grown on PDA in the presence or absence of L-38; (B) Conidial characteristics of $A$. flavus under microscopic examination cultured in the presence or absence of L-38 at 3 dpi, Bar=10 $\mu \mathrm{m}$.

was $100 \%$, compared to control plates lacking L-38 (Figure $2 \mathrm{~A}, \mathrm{~B})$. In contrast, conidia in control plates germinated to form hyphae and the mycelia quickly spread over the whole PDA plate within 3 days (Figure 2A). The cell morphology of conidia under microscopy confirmed our results in that conidia germinated to hyphae and grew well in the control plates, but no conidia germinated in the presence of L-38 at 3 dpi. This initial test showed that strain L-38 can completely inhibit conidial germination and mycelial growth in a sealed airspace environment through the production of VOCs.

\section{Identification of the antifungal compounds from Staphylococcus saprophyticus L-38}

VOCs from strain L-38 were collected by SPME syringe and analysed with GC-MS. The compounds found in the airspace of L-38 in NA plates, but not in the control treatment (without L-38 strain) were considered to be the VOCs produced by L-38. This experiment resulted in detection of 7 putative VOCs (Figure 3 and Table 1). These VOCs were classified into several chemical classes, including glucopyranosides, epoxybutanes, phenylacetylenes, phenol, benzeneacetic acids, and cyclononasiloxanes. The compound with the great relative abundance (of the total peak area over $1 \%$ ) and the highest similarity (over $70 \%$ ) was selected for further study. Only one compound, 3,3-dimethyl-1,2epoxybutane (3-DE), with a highest relative abundance of $32.61 \%$, was analysed in detail. The molecular mass of 3-DE is 100.089 Daltons. The retention time was $4.219 \mathrm{~min}$, and the similarity is $78 \%$ to the National Institute of Standards and Technology (NIST) 08 MS database. 

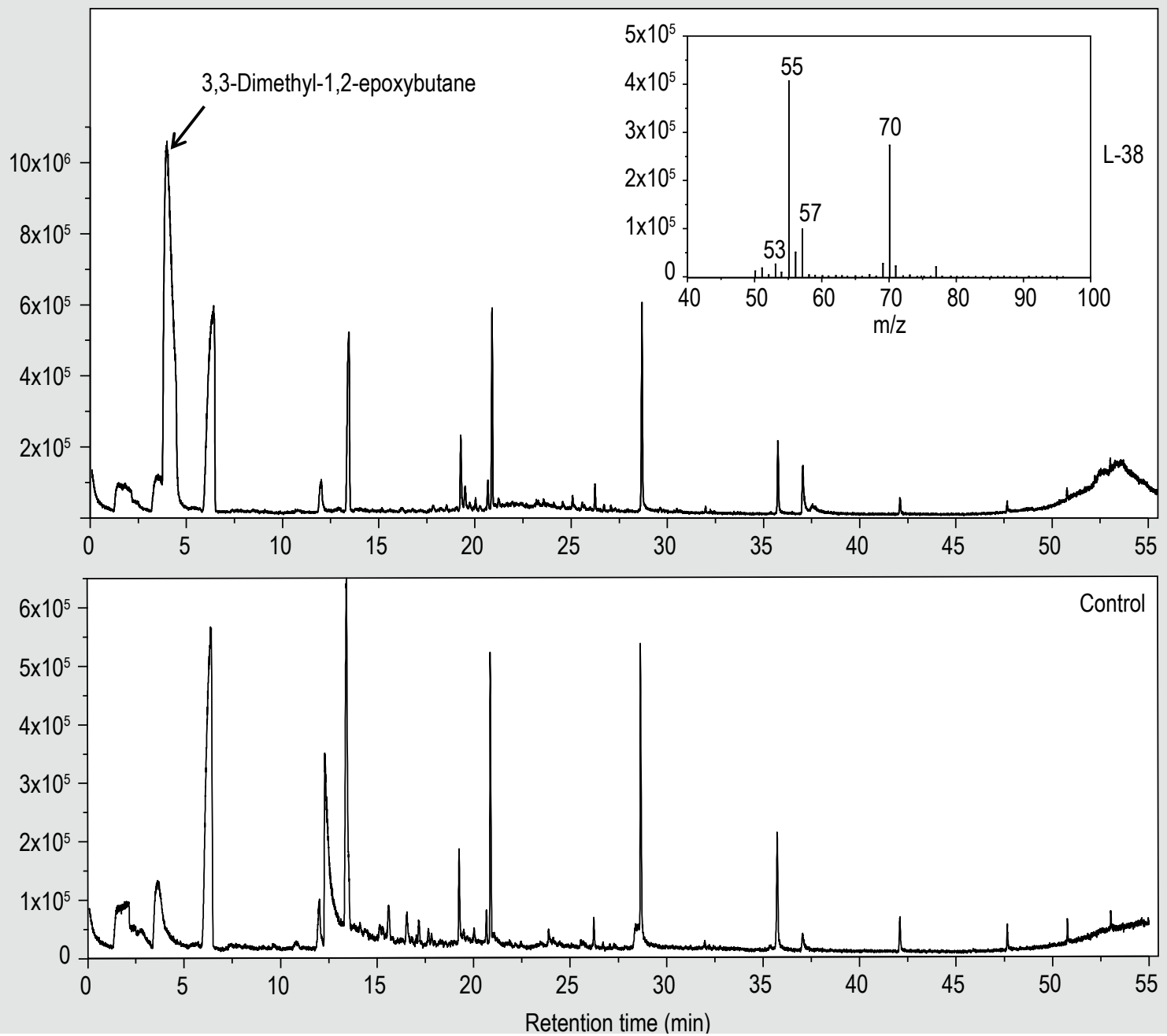

Figure 3. GC-MS spectra of volatiles emitted from Staphylococcus saprophyticus strain L-38. Volatiles were detected in airspace of NA plates at 2 dpi with (L-38) or without (Control) the presence of strain L-38. The insert shows the mass spectrum analysis of the $L-38$ peak at $R T=4.219$ min.

Table 1. GC-MS analysis of volatiles from Staphylococcus saprophyticus strain L-38 grown on NA plates.

\begin{tabular}{|c|c|c|c|c|c|}
\hline Compounds & $\operatorname{Rt}(\min )^{1}$ & $\mathrm{Ra}^{2}$ & $\mathrm{Sl}^{3}(\%)$ & $\mathrm{MW}^{4}$ & $\mathrm{CAS}^{5}$ \\
\hline $\begin{array}{l}\text { alpha-D-glucopyranoside, methyl 2-(acetylamino)-2-deoxy-3-O- } \\
\text { (trimethylsilyl)-, cyclic methylboronate }\end{array}$ & 1.404 & 0.21 & 58 & 331.16 & $054477-01-9$ \\
\hline 3,3-Dimethyl-1,2-epoxybutane ${ }^{6}$ & 4.219 & 32.61 & 78 & 100.09 & $002245-30-9$ \\
\hline Fluoren-9-ol, 3,6-dimethoxy-9-(2-phenylethynyl)- & 20.676 & 0.691 & 46 & 342.13 & $1000217-31-2$ \\
\hline Phenol, 2,4-bis(1,1-dimethylethyl)- & 37.555 & 0.07 & 68 & 206.17 & 000096-76-4 \\
\hline Benzeneacetic acid, alpha,3,4-tris[(trimethylsily)|)oxy]-, trimethylsilyl ester & 42.099 & 0.44 & 38 & 472.19 & 037148-65-5 \\
\hline Cyclononasiloxane, octadecamethyl- & 47.672 & 0.20 & 59 & 666.17 & 000556-71-8 \\
\hline Cyclodecasiloxane, eicosamethyl- & 50.779 & 0.16 & 46 & 740.19 & 018772-36-6 \\
\hline
\end{tabular}

\footnotetext{
${ }^{1}$ Retention time of detected compounds in GC-MS chromatogram.

${ }^{2}$ Relative area of identified compound to the total area of the chromatographic peaks.

${ }^{3}$ Similarity of analyte spectra with entries in the NIST 08 MS spectral database.

${ }^{4}$ Molecular weight of identified compound.

${ }^{5}$ Chemical Abstracts Service (CAS) registry number.

${ }^{6}$ The compounds with relative abundance over $1 \%$, similarity over $70 \%$ were selected for antifungal tests.
} 
To determine the potential activity of 3-DE, we purchased a 3-DE standard and tested it for antifungal activity in the absence of L-38. To accomplish this, we cultured $A$. flavus in the presence of different concentrations of 3-DE in sealed petri dishes to test for variation in antifungal activity. The results clearly showed that 3-DE quickly evaporated, and its addition to media greatly inhibited A. flavus mycelial growth at concentrations ranging from 5 to $200 \mu \mathrm{g} / \mathrm{l}$ (compound weight/airspace volume). The inhibition rate was between 11.96 to $100 \%$. The minimal inhibitory concentration (MIC) of 3-DE against growth of A. flavus mycelium was $200 \mu \mathrm{g} / \mathrm{l}$ (Figure 4). These results confirmed that 3-DE produced by strain L-38 was the main factor causing $A$. flavus inhibition. Moreover, the abundance of 3-DE among L-38 VOCs was higher than the MIC concentration, and completely inhibited A. flavus germination and growth.

\section{Biocontrol activity of strain L-38 on maize and peanut}

It is well-established that the $\mathrm{a}_{\mathrm{w}}$ level of post-harvest crops is a strong contributor to pathogen infestation and mycotoxin production (Mannaa and Kim, 2017). High $\mathrm{a}_{\mathrm{w}}$ levels are typically conducive to severe food spoilage. To gain insight into the effects of water activity on the efficacy of L-38, we examined the growth of $A$. flavus and production of aflatoxin in the presence of L-38 on peanut and maize substrate at two different levels of $a_{w}$ in an enclosed desiccator. We clearly observed that the infestation of peanuts and maize at $\mathrm{a}_{\mathrm{w}} 0.92$ was more severe than at $a_{w} 0.86$ in the control (Figure 5). The kernel surfaces were profusely covered with conidia and mycelia. In the control, the disease incidence of peanuts was $100 \%$ both at $\mathrm{a}_{\mathrm{w}} 0.86$ and 0.92 , respectively, while the disease incidence of maize was 88 , and $98 \%$ at $\mathrm{a}_{\mathrm{w}} 0.86$ and 0.92 , respectively. In the L-38 treatment, $A$. flavus disease on maize and peanuts was greatly inhibited at both $\mathrm{a}_{\mathrm{w}}$ levels. These results strongly suggest that L-38 showed effective biocontrol activity against $A$. flavus development and germination on postharvest substrates through the emission of VOCs.

In order to measure differences in aflatoxin production resulting from treatment with L-38, LC-ESI-MS was used to measure toxin accumulation on the peanut and maize samples. Two aflatoxins including $\mathrm{AFB}_{1}$ and $\mathrm{AFB}_{2}$ were detected in the control samples at $5 \mathrm{dpi}$. In the peanut control, which was not exposed to cultures of L-38, the total aflatoxins were 0.70 and $4.90 \mu \mathrm{g} / \mathrm{g}$ at $\mathrm{a}_{\mathrm{w}} 0.86$ and 0.92 , respectively. In the maize control, the aflatoxin contents were 1.30 and $2.50 \mu \mathrm{g} / \mathrm{g}$ at $\mathrm{a}_{\mathrm{w}} 0.86$ and 0.92 , respectively. The high toxicity compounds $\mathrm{AFB}_{1}$ were more abundant than $\mathrm{AFB}_{2}$ in each treatment. In contrast, no aflatoxin was detected in any of the peanut or maize samples treated with L-38. We concluded that the L-38 strain was able to completely prevent the production of aflatoxins in crops at high $\mathrm{a}_{\mathrm{w}}$. Furthermore, 3-DE released by L-38 was most likely responsible for strong inhibition of aflatoxin production in both maize and peanut, and at two different $\mathrm{a}_{\mathrm{w}}$ values conducive to microbial growth.

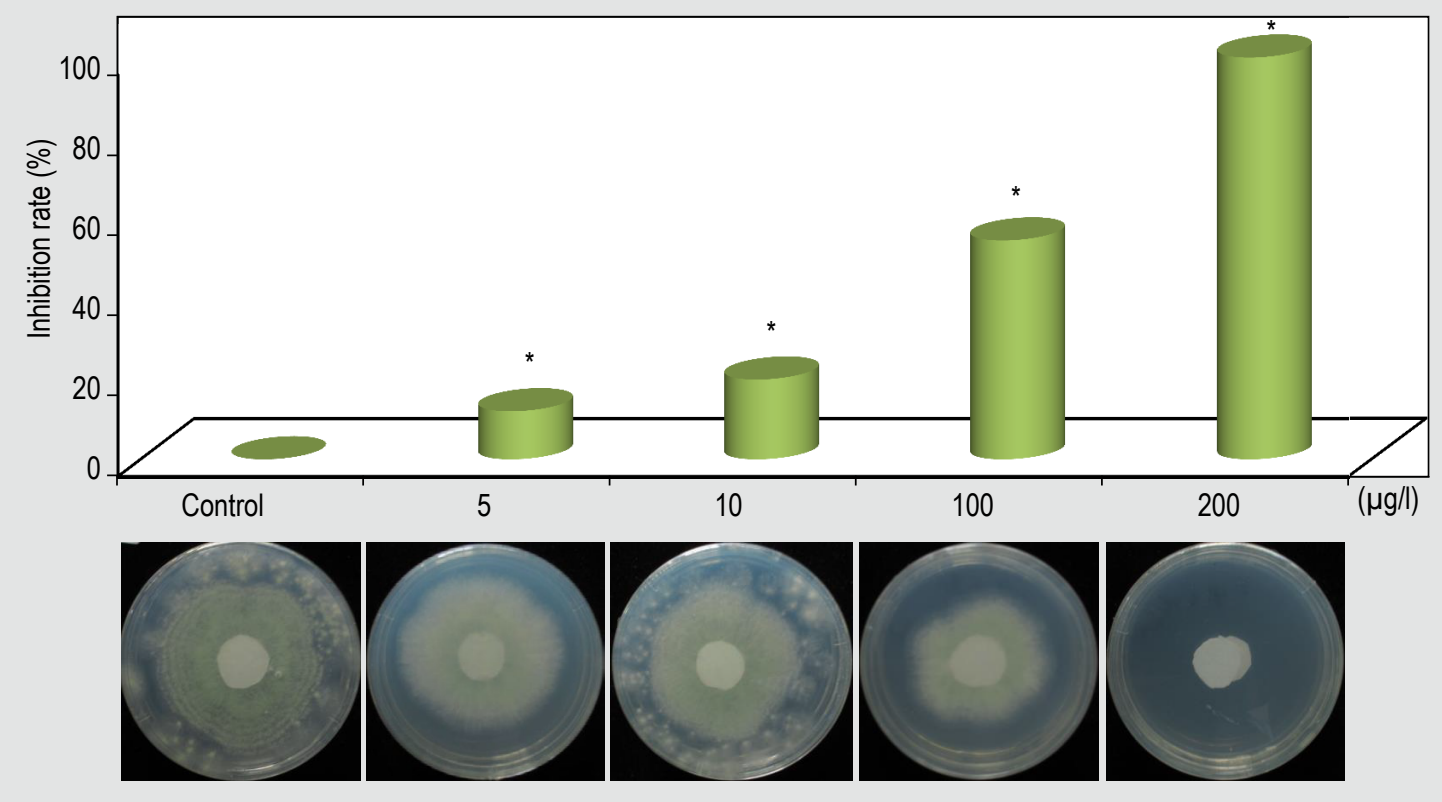

Figure 4. Inhibitory effect of 3-DE on the mycelial growth of Aspergillus flavus. Volatile compound 3-DE was serially diluted to 5, 10,100 and $200 \mu \mathrm{g} / \mathrm{l}$ (compound weight to airspace volume) and tested the inhibition activity on mycelial growth of $A$. flavus on potato dextrose agar (PDA). The inhibition rate $(\%)=$ (diameter in control - diameter in L-38 treatment)/ diameter in control $\times 100$. * means significantly different compared to control treatment at $P<0.05$. 


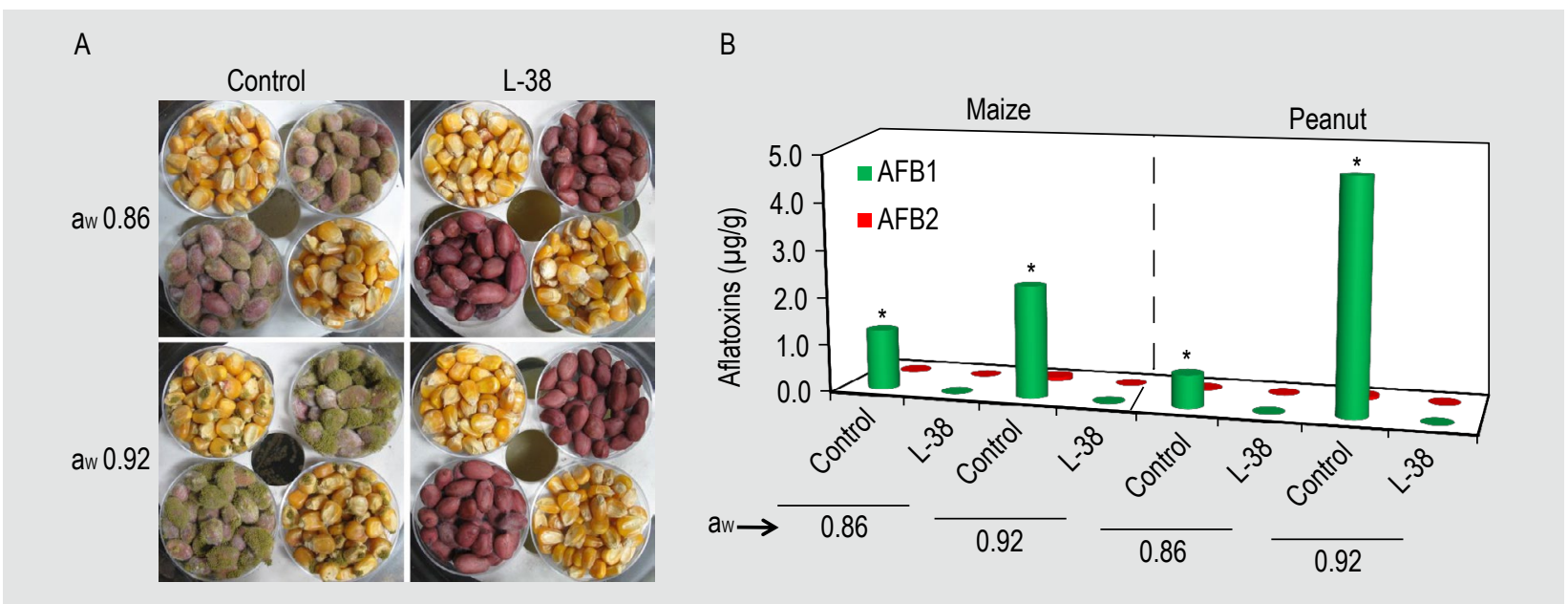

Figure 5. Efficacy of Staphylococcus saprophyticus strain L-38 for biocontrol against Aspergillus flavus and aflatoxin production in peanuts and maize. (A) Disease phenotypes of peanuts and maize infected with $A$. flavus in the presence or absence (control) of strain L-38 at $28{ }^{\circ} \mathrm{C}$ for 5 days. (B) Aflatoxin content in peanut and maize samples was detected through LC-ESI-MS with two replications. * means significantly different compared to control treatment at $P<0.05$.

\section{Ultra-structural changes of Aspergillus flavus inoculated on peanut surface induced by L-38}

To observe changes in A. flavus morphology induced by L-38 exposure, SEM was used to examine the ultrastructure of $A$. flavus inoculated to peanut with $\mathrm{a}_{\mathrm{w}} 0.92$ at $5 \mathrm{dpi}$. In the control samples not exposed to L-38, A. flavus mycelia covered the whole peanut surface accompanied by production of green conidia (Figure 6). However, in A. flavus-inoculated peanut samples in the presence of L-38, we observed very few, extremely thin, undeveloped conidia on peanut kernels (Figure 6). Only few conidia developed on the peanut surface, which did not germinate to form mycelia, with no production of conidiophores. Further, conidia treated with L-38 were severely deformed, exhibiting irregular shapes with curves on the surface. Thus, strain L-38 caused various severe damages to $A$. flavus cell structure, inhibited the cell growth, germination, and conidiophores production, and ultimately preventing $A$. flavus infection and aflatoxin production in kernels.

\section{Broad spectrum antifungal activity of strain L-38 against nine phytopathogenic fungi}

Eight highly destructive phytopathogenic fungi in addition to $A$. flavus were used to test the broad antifungal activity of strain L-38, including $A$. niger, $F$. verticillioides, $F$. graminearum, S. sclerotiorum, $R$. solani, A. alternata, $M$. fructicola, and $B$. cinerea in a sealed chamber. The inhibition rate was calculated at $5 \mathrm{dpi}$ in each assay. As shown in Figure 7, the mycelia in control groups lacking L-38 spread extensively over the culture medium, while in L-38 treatment, 3-DE greatly inhibited the growth of all fungi. Except F. graminearum (92\%), the inhibition rate of L-38 against mycelial growth among all other fungi was

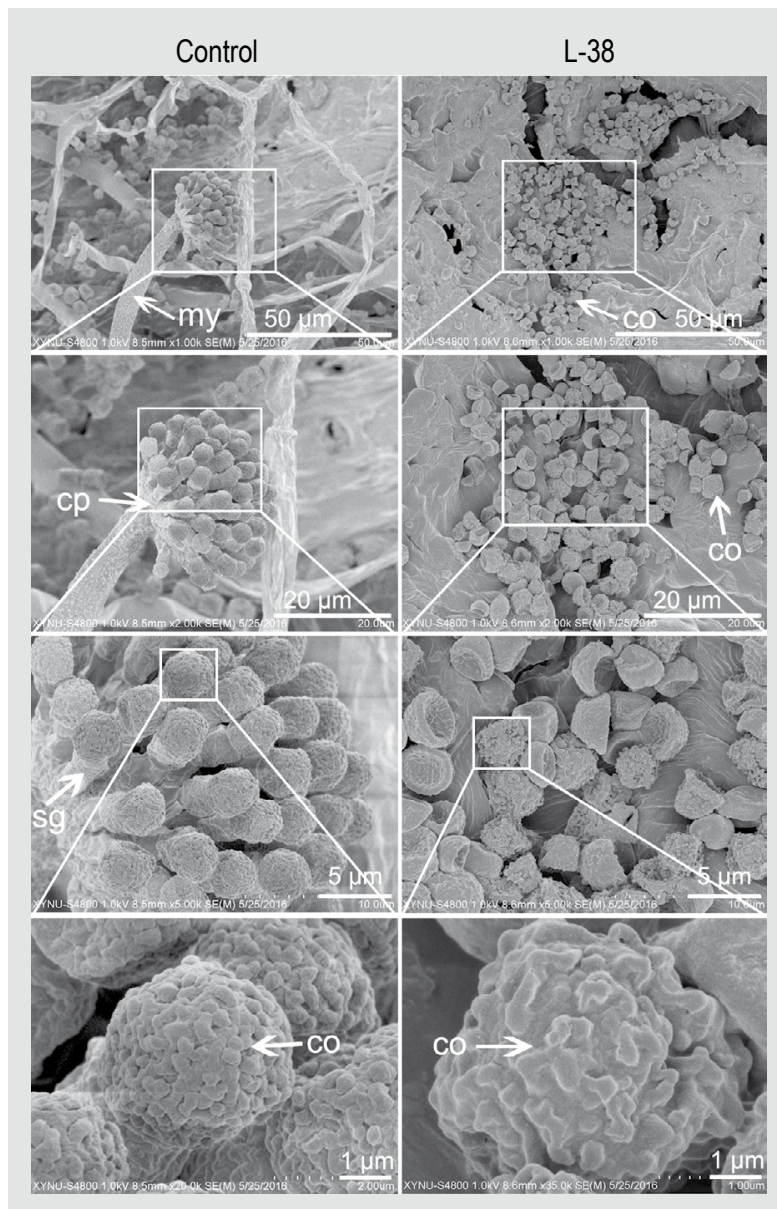

Figure 6. Scanning electron microscopy of Aspergillus flavus growing on infected peanuts. Peanuts with a water activity $\left(\mathrm{a}_{\mathrm{w}}\right)$ of 0.92 were inoculated with $A$. flavus conidia and incubated in the presence or absence (control) of Staphylococcus saprophyticus strain L-38. co: conidia, cp: conidiophore, my: mycelia, sg: sterigma. 


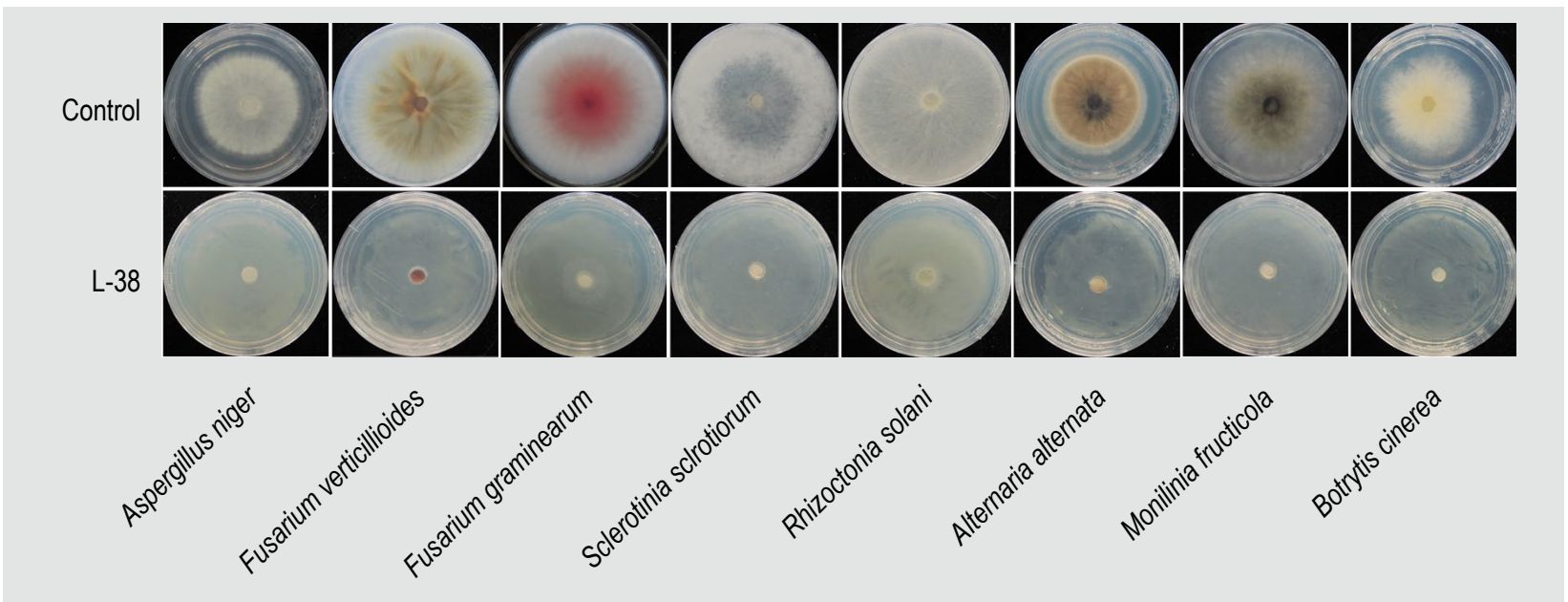

Figure 7. Antifungal activity of Staphylococcus saprophyticus strain L-38 against eight selected phyto-pathogenic fungi. Top panel: Fungal mycelia in the absence of the strain L-38 (Control); Bottom panel: Fungal mycelia in the presence of the strain L-38.

$100 \%$. These results demonstrate that strain L-38 has a wide spectrum of inhibitory activity against conidial germination and hyphal development by phytopathogenic fungi from different genera.

\section{Discussion}

A. flavus and the carcinogenic aflatoxins it produces cause considerable deleterious effects to humans in all parts of the world. The prevention of A. flavus and aflatoxin contamination is considered an essential priority in food production and storage processes. Here, we presented the marine bacterium L-38, identified as Staphylococcus saprophyticus, which showed strong biocontrol activity against $A$. flavus infestation and aflatoxin production in post-harvest maize and peanut. The mechanism of inhibition ostensibly relies on the production of volatile compounds, which substantially reduce the mycelial colonisation and conidial germination on food substrates in a sealed airspace, both in vitro and in vivo, as well as reducing the production of aflatoxins.

S. saprophyticus are gram positive bacteria which are seldom reported to be hazardous to humans, with the exception of common urinary tract infections in young women. However, the biological capability of $S$. saprophyticus for volatile secondary metabolite production was not previously known. In our tests, we are the first to demonstrate that $S$. saprophyticus L-38 could be used as an effective antagonist strain in the control of fungal diseases via production of volatile compounds. Strain L-38 completely inhibited conidial germination and mycelial growth over 3 days of co-culture (Figure 2). The conidia on PDA plates challenged with L-38 (without contact) failed to germinate, though mycelia and conidia in control groups grew well. Hence, we concluded that strain L-38 produced some volatile compounds which permeated the sealed airspace, and prevented fungal cell development. Additionally, we also showed that L-38 inhibits the growth of 8 other fungal plant pathogens that cause serious losses in food production. This report thus opens a new area for the study of $S$. saprophyticus strains in post-harvest biological control.

As we all know that marine environments cover more than $70 \%$ of the earth's surface, comprising a huge ecosystem with abundant useful and novel microbial strains. Many microbes, as well as their metabolites, have been broadly used across a wide range of applications in our society (Araujo et al., 2015; Tedesco et al., 2016; Yan et al., 2016). Screening of marine sediments as a resource for effective antifungal microbes to control $A$. flavus and aflatoxins is currently a promising strategy for developing new avenues of research. To this effect, we isolated strain L-38 through a screen for antifungal volatile production and subsequently characterised its volatile profile using an SPME-GC/MS system. We found that L-38 produced 7 volatile, putatively anti-fungal compounds. Among these compounds, 3-DE was the most abundant fraction.

Pure 3-DE, in the absence of L-38, showed valid inhibitory effects on $A$. flavus cells. The MIC of 3-DE for A. flavus cells was $200 \mu \mathrm{g} / \mathrm{l}$ (compound weight/air space volume) in a sealed airspace. This result strongly suggested that inhibition of growth and germination by L-38 relies on the production of volatile $3-\mathrm{DE}$. The structure of $3-\mathrm{DE}$ is an epoxybutane with two methyl on the side chains. Until now, the compound 3-DE was primarily used in chemical synthesis processes (Fuchs et al., 2013). However, this is the first report to our knowledge concerning the biological activity of this compound. In our tests we first showed that 3-DE was produced by S. saprophyticus L-38, and subsequently, we revealed that 3-DE can be used as a biocontrol agent to inhibit fungal cell growth in vitro and in vivo. Further inhibition kinetics studies of volatile 3-DE 
against $A$. flavus growth will provide novel applications for the most efficient use of this strain and a better understanding its mechanism of action.

It has also been widely reported that $A$. flavus is an airborne fungus that causes huge damage because of how easily and widely its conidia spread and infect new fields and storage houses (Bediako et al., 2018). Hence, the most effective method to control A. flavus disease currently in practice is to prevent conidial germination on crops at post-harvest. In our tests, we clearly observed under SEM that conidia on peanut surfaces, in the absence of L-38 treatment, germinate into mycelium, develop into conidiophores, and produce numerous fresh conidia. In contrast, in the L-38 treatment, the conidia on peanut surfaces did not germinate and their structure was severely damaged under the influence of L-38 VOCs. SEM thus provides strong visual evidence for the effectiveness of strain L-38 VOCs. We observed damage to conidial cell structure, abolition of mycelia growth, and prevention of fungal colonisation and aflatoxin production. For example, the $\mathrm{AFB}_{1}$ content in untreated maize and peanut samples (aw $=0.86$ and 0.92 ) was much higher than the maximum limit set by the WHO $(5 \mu \mathrm{g} / \mathrm{kg})$ and European Union $(2$ $\mu \mathrm{g} / \mathrm{kg}$ ) (Passone and Etcheverry, 2014), whereas in maize and peanut samples exposed to $\mathrm{L}-38$ cultures $\left(\mathrm{a}_{\mathrm{w}}=0.86\right.$ and 0.92), no aflatoxin was detected.

These assays demonstrate that microbial VOCs are not restricted to in vitro inhibition of mycelial growth, but could also be used as fumigants for the control of soil-borne fungal pathogens. Dimethyl disulphide (DMDS) is a volatile microbial compound that has been applied in different crops to provide satisfactory control of root knot nematodes and cyst nematodes (Curto et al., 2014; Fritsch et al., 2014; Sasanelli et al., 2014), as well as other soil pathogens such as Sclerotium rolfsii, Verticillium dahlia, and $R$. solani (Fritsch, 2004). Recently, Papazlatani demonstrated that DMDS exhibits strong antifungal activity, and that even at low doses $\left(56.4 \mathrm{~g} \mathrm{~m}^{-2}\right)$ it can dramatically decrease populations of soil-borne pathogens of tomato, such as $F$. oxysporum and R. solani (Papazlatani et al., 2016). Another volatile, caryophyllene, from the antagonistic strain $F$. oxysporum MSA35 can repress the expression of two putative virulence genes in pathogenic F. oxysporum pv. lactucae, which influences the mycelial growth and represses disease (Minerdi et al., 2009). These findings open insights into new applications for volatile compounds, including 3-DE, which was found in our tests. Thus, the application of VOCs for controlling fungal pathogens in airspace, as well as in soil and other conditions may be viable, sound, and novel environmental control strategies.

In our results, 3-DE produced by marine bacterium L-38 showed broad antifungal activity against 9 important plant pathogens. These nine pathogens were of different genera with diverse cell compositions, physiology, ecological niches, life cycles, and host crops. This finding provides the basis for broad application of 3-DE as a biocontrol agent against these plant pathogens in different ecosystems. Although the antagonistic mechanism of 3-DE on A. flavus has yet to be determined, the interactions between L-38 and these fungi may serve as an ideal starting point for elucidation of the molecular mechanisms of 3-DE inhibition of growth and germination in filamentous fungi. The broad biological applications and mechanisms of antagonism by compound 3-DE against $A$. flavus will be of great interest in further studies.

\section{Conclusions}

In conclusion, the marine sediment bacterium $S$. saprophyticus L-38 robustly inhibited A. flavus conidial germination and mycelial proliferation in vitro through the abundant production of the anti-fungal compound 3-DE. L-38 produced 3-DE with a MIC of $200 \mu \mathrm{g} / \mathrm{l}$ against $A$. flavus, suggesting its potential use as an effective fumigant in controlling A. flavus on peanuts and maize in storage or in field soil. It also shows severe, adverse effects on fungal cell structure and completely prevents aflatoxin productions. Moreover, L-38 exhibited broad antifungal activity against 8 important fungal pathogens in addition to A. flavus, with almost complete inhibition of growth among these pathogens. We conclude from these experimental data that strain L-38 or purified 3-DE will have extensive application in controlling soil-borne and post-harvest fungal pathogens.

\section{Acknowledgements}

This work was supported by the National Key R\&D Program of China (2018YFD0200506, 2016YFE0112900) and the National Basic Research Program of China (2013CB127801). The authors would also like to acknowledge the financial support from National Natural Science Foundation of China (31701740), Nanhu Scholars Program for Young Scholars of XYNU, Scientific and Technological Project in Henan Province (182102110018) and the Fundamental Research Funds for the Central Universities (Program No. 2662016PY076).

\section{Conflict of interest}

The authors declare no conflict of interest.

\section{References}

Amaike, S. and Keller, N.P., 2011. Aspergillus flavus. Annual Review of Phytopathology 49: 107-133.

Araujo, A.C.V., Abreu, F., Silva, K.T., Bazylinski, D.A. and Lins, U., 2015. Magnetotactic bacteria as potential sources of bioproducts. Marine Drugs 13: 389-430. 
Ashworth, L.J., Schroeder, H.W. and Langley, B.C., 1965. Aflatoxins: environmental factors governing occurrence in Spanish peanuts. Science 148: 1228-1229.

Asters, M.C., Williams, W.P., Perkins, A.D., Mylroie, J.E., Windham, G.L. and Shan, X.Y., 2014. Relating significance and relations of differentially expressed genes in response to Aspergillus flavus infection in maize. Scientific Reports 4: 4815.

Bediako, K.A., Ofori, K., Offei, S.K., Dzidzienyo, D., Asibuo, J.Y. and Amoah, R.A., 2018. Aflatoxin contamination of groundnut (Arachis hypogaea $\mathrm{L}$.): predisposing factors and management interventions. Food Control 98: 61-67.

Boukaew, S. and Prasertsan, P., 2014. Suppression of rice sheath blight disease using a heat stable culture filtrate from Streptomyces philanthi RM-1-138. Crop Protect 61: 1-10.

Buchanan, R.L., Jones, S.B. and Stahl, H.G., 1987. Effect of miconazole on growth and aflatoxin production by Aspergillus parasiticus. Mycopathologia 100: 135-144.

Bui-Klimke, T.R., Guclu, H., Kensler, T.W., Yuan, J.M. and Wu, F., 2014. Aflatoxin regulations and global pistachio trade: insights from social network analysis. PLoS ONE 9: e92149.

Cleveland, T.E., Carter-Wientjes, C.H., De Lucca, A.J. and Boue, S.M., 2009. Effect of soybean volatile compounds on Aspergillus flavus growth and aflatoxin production. Journal of Food Science 74: H83-H87.

Curto, G., Dongiovanni, C., Sasanelli, N., Santori, A. and Myrta, A., 2014. Efficacy of dimethyl disulfide (DMDS) in the control of the root-knot nematode Meloidogyne incognita and the cyst nematode Heterodera carotae on carrot in field condition in Italy. VIII International Symposium on Chemical and Non-Chemical Soil and Substrate Disinfestation. Acta Horticulturae 1044: 405-410.

Ding, W., Si, M., Zhang, W.P., Zhang, Y.L., Chen, C., Zhang, L., Lu, Z.Q., Chen, S.L. and Shen, X.H., 2015. Functional characterization of a vanillin dehydrogenase in Corynebacterium glutamicum. Scienfic Reports 5: 8044.

Dorner, J.W., 2004. Biological control of aflatoxin contamination of crops. Journal of Toxicology: Toxin Review 23: 425-450.

Fernando, W.G.D., Ramarathnam, R., Krishnamoorthy, A.S. and Savchuk, S.C., 2005. Identification and use of potential bacterial organic antifungal volatiles in biocontrol. Soil Biology and Biochemistry 37: 955-964.

Fritsch, J., 2004. Dimethyl disulfide as a new chemical potential alternative to methyl bromide in soil disinfestation in France. Acta Horticulturae 698: 71-76.

Fritsch, J., Fouillet, T., Charles, P., Fargier-Puech, P., Ramponi-Bur, C., Descamps, S., Fretay, G.D. and Myrta, A., 2014. French experiences with dimethyl disulfide (DMDS) as a nematicide in vegetable crops. Acta Horticulturae 1044: 427-433.

Fuchs, M.A., Zevaco, T.A., Ember, E., Walter, O., Held, I., Dinjus, E. and Döring, M., 2013. Synthesis of cyclic carbonates from epoxides and carbon dioxide catalyzed by an easy-to-handle ionic iron (III) complex. Dalton Transactions 42: 5322-5329.

Gao, W., Xu, F.C., Guo, D.D., Zhao, J.R., Liu, J., Guo, Y.W., Singh, P.K., Ma, X.N., Long, L., Botella, J.R. and Song, C.P., 2018. Calciumdependent protein kinases in cotton: insights into early plant responses to salt stress. BMC Plant Biology 18: 15.
Gong, A.D., Li, H.P., Shen, L., Zhang, J.B., Wu, A.B., He, W.J., Yuan, Q.S., He, J.D. and Liao, Y.C., 2015a. The Shewanella algae strain YM8 produces volatiles with strong inhibition activity against Aspergillus pathogens and aflatoxins. Frontiers in Microbiology 6: 1091.

Gong, A.D., Li, H.P., Yuan, Q.S., Song, X.S., Yao, W., He, W.J., Zhang, J.B. and Liao, Y.C., 2015b. Antagonistic mechanism of iturin A and plipastatin A from Bacillus amyloliquefaciens S76-3 from wheat spikes against Fusarium graminearum. PLoS ONE 10: e0116871.

Guo, Y.W., Guo, H.L., Li, X., Huang, L.L., Zhang, B.N., Pang, X.B., Liu, B.Y., Ma, L.Q. and Wang, H., 2013. Two type III polyketide synthases from Polygonum cuspidatum: gene structure, evolutionary route and metabolites. Plant Biotechnology Reports 7: 371-381.

Han, Y.J., Chen, W.C., Yang, F.B., Wang, X.H., Dong, M.F., Zhou, P. and Shang, F.D., 2015. cDNA-AFLP analysis on 2 Osmanthus fragrans cultivars with different flower color and molecular characteristics of OfMYB1 gene. Trees-Structure and Function 29: 931-940.

International Agency for Research on Cancer (IARC), 2002. IARC Monographs on the evaluation of carcinogenic risks to humans. Vol. 82. IARC Press, Lyon, France.

Kamika, I. and Takoy, L.L., 2011. Natural occurrence of aflatoxin $B_{1}$ in peanut collected from Kinshasa, Democratic Republic of Congo. Food Control 22: 1760-1764.

Kedia, A., Prakash, B., Mishra, P.K. and Dubey, N.K., 2014. Antifungal and antiaflatoxigenic properties of Cuminum cyminum (L.) seed essential oil and its efficacy as a preservative in stored commodities. International Journal of Food Microbiology 168-169: 1-7.

Kelecom, A., 2002. Secondary metabolites from marine microorganisms. Anais Da Academia Brasileira De Ciências 74: 151-170.

Kirk, G.D., Bah, E. and Montesano, R., 2006. Molecular epidemiology of human liver cancer: insights into etiology, pathogenesis and prevention from The Gambia, West Africa. Journal of Carcinogenesis 27: 2070-2082.

Kloos, W.E. and Schleifer, K.H., 1975. Simplified scheme for routine identification of human Staphylococcus species. Journal of Clinical Microbiology 1: 82-88.

Kuang, S.Y., Lekawanvijit, S., Maneekarn, N., Thongsawat, S., Brodovicz, K., Nelson, K., Nelson, K. and Groopman, J.D., 2005. Hepatitis B $1762^{\mathrm{T}} / 1764^{\mathrm{A}}$ mutations, hepatitis $\mathrm{C}$ infection, and codon 249 p53 mutations in hepatocellular carcinomas from Thailand. Cancer Epidemiology Biomarkers and Prevention 14: 380-384.

Li, H., Fan, H.C., Li, Y.R., Shi, G.Y., Ding, Z.Y., Gu, Z.H. and Zhang, L., 2017. Construction and application of multi-host integrative vector system for xylose-fermenting yeast. FEMS Yeast Research 17: 10.

Malachová, A., Sulyok, M., Beltrán, E., Berthiller, F. and Krska, R., 2014. Optimization and validation of a quantitative liquid chromatography-tandem mass spectrometric method covering 295 bacterial and fungal metabolites including all regulated mycotoxins in four model food matrices. Journal of Chromatography A 1362: 145-156.

Mannaa, M. and Kim, K.D., 2017. Influence of temperature and water activity on deleterious fungi and mycotoxin production during grain storage. Mycobiology 45: 240-254. 
Minerdi, D., Bossi, S., Gullino, M.L. and Garibaldi, A., 2009. Volatile organic compounds: a potential direct long-distance mechanism for antagonistic action of Fusarium oxysporum strain MSA 35. Environmental Microbiology 11: 844-854.

Ogodo, A.C. and Ugbogu, O.C., 2016. Public health significance of aflatoxin in food industry - a review. European Journal of Clinical and Biomedical Sciences 2: 51-58.

Papazlatani, C., Rousidou, C., Katsoula, A., Kolyvas, M., Genitsaris, S., Papadopoulou, K.K. and Karpouzas, D.G., 2016. Assessment of the impact of the fumigant dimethyl disulfide on the dynamics of major fungal plant pathogens in greenhouse soils. European Journal of Plant Pathology 146: 391-400.

Paranagama, P.A., Abeysekera, K.H.T., Abeywickrama, K. and Nugaliyadde, L., 2003. Fungicidal and anti-aflatoxigenic effects of the essential oil of Cymbopogon citratus (DC.) Stapf. (lemongrass) against Aspergillus flavus Link. isolated from stored rice. Letters in Applied Microbiology 37: 86-90.

Passone, M.A. and Etcheverry, M., 2014. Antifungal impact of volatile fractions of Peumus boldus and Lippia turbinata on Aspergillus section Flavi and residual levels of these oils in irradiated peanut. International Journal of Food Microbiology 168-169: 17-23.

Robens, J. and Cardwell, K., 2003. The costs of mycotoxin management to the USA: management of aflatoxins in the United States. Journal of Toxicology: Toxin Review 22: 139-152.

Sasanelli, N., Dongiovanni, C., Santori, A. and Myrta, A., 2014. Control of the root-knot Meloidogyne incognita by dimethyl disulfide (DMDS) applied in drip irrigation on melon and tomato in Apulia and Basilicata (Italy). Acta Horticulturae 1044: 401-404.

Schleifer, K.H. and Kloos, W.E., 1975. Isolation and characterization of Staphylococci from human skin I. Amended descriptions of Staphylococcus epidermidis and Staphylococcus saprophyticus and descriptions of three new species: Staphylococcus cohnii, Staphylococcus haemolyticus, and Staphylococcus xylosus. International Journal of Systematic Bacteriology 25: 50-61.
Strosnider, H., Azziz-Baumgartner, E., Banziger, M., Bhat, R.V., Breiman, R., Brune, M., DeCock, K., Dilley, A., Groopman, J. and Hell, K., 2006. Workgroup report: public health strategies for reducing aflatoxin exposure in developing countries. Environmental Health Perspective 114: 1898-1903.

Tedesco, P., Maida, I., Palma Esposito, F., Tortorella, E., Subko, K., Ezeofor, C.C., Zhang, Y., Tabudravu, J., Jaspars, M., Fani, R. and De Pascale, D., 2016. Antimicrobial activity of monoramnholipids produced by bacterial strains isolated from the ross sea (Antarctica). Marine Drugs 14: 83.

Thobunluepop, P., 2009. The inhibitory effect of the various seed coating substances against rice seed borne fungi and their shelf-life during storage. Pakistan Journal of Biological Sciences 12: 1102-1110.

Waliyar, F., Umeh, V.C., Traore, A., Osiru, M., Ntare, B.R., Diarra, B., Kodio, O., Kumar, K.V.K. and Sudini, H., 2015. Prevalence and distribution of aflatoxin contamination in groundnut (Arachis hypogaea L.) in Mali, West Africa. Crop Protection 70: 1-7.

Wicklow, D.T., Hesseltine, C.W., Shotwell, O.L. and Adams, G.L., 1980. Interference competition and aflatoxin levels in corn. Phytopathology 70: 761-764.

Wild, C.P. and Montesano, R., 2009. A model of interaction: aflatoxins and hepatitis viruses in liver cancer aetiology and prevention. Cancer Letters 286: 22-28.

Wu, F. and Khlangwiset, P., 2010. Evaluating the technical feasibility of aflatoxin risk reduction strategies in Africa. Food Additives Contaminants Part A 27: 658-676.

Yan, X., Zhou, Y.X., Tang, X.X., Liu, X.X., Yi, Z.W., Fang, M.J., Wu, Z., Jiang, F.Q. and Qiu, Y.K., 2016. Macrolactins from marine-derived Bacillus subtilis B5 bacteria as inhibitors of inducible nitric oxide and cytokines expression. Marine Drugs 14: 195.

Zhang, H.F., Yang, X.H. and Wang, Y., 2011. Microwave assisted extraction of secondary metabolites from plants: current status and future directions. Trends in Food Science and Technology 22: 672-688. 